\title{
Tornar a Revolta Impossível
}

[Making Revolt Impossible ]

\author{
Thomas Berns ${ }^{\Uparrow}$
}

Tradução

Maria Cecília Pedreira de Almeidai , Marco Antonio Sousa Alvesii

\begin{abstract}
Resumo: Neste artigo, publicado originalmente na França (Rendre la révolte impossible, Rue Descartes, 2013/1, n. 77, pp. 121-128), Thomas Berns reflete sobre um novo tipo de normatividade, que se afasta do modelo jurídico-discursivo e subverte um aspecto fundamental daquilo que entendemos tradicionalmente por norma: a possibilidade de desobediência. O autor procura discernir, nas normatividades contemporâneas, uma nova relação com a realidade, uma pretensão de governar a partir do real. Diferentemente da norma jurídica, que expressa um ato de vontade que procura governar o real, tais normatividades são concebidas como imanentes ao real, permitindo que as práticas de governo se tornem mais insidiosas, quase imperceptíveis, como vemos na "governamentalidade algorítmica". A tradução deste artigo para o português procura contribuir para a difusão, no Brasil, desse importante debate sobre a política e o direito na contemporaneidade.

Palavras-chave: Normatividade. Desobediência. Governamentalidade Algorítmica.
\end{abstract}

\begin{abstract}
In this article, originally published in France (Rendre la révolte impossible, Rue Descartes, 2013/1, n. 77, pp. 121-128), Thomas Berns reflects on a new kind of normativity, which departs from the legal-discursive model and subverts a fundamental aspect of what we traditionally understand by norm: the possibility of disobedience. The author seeks to discern, in contemporary normativities, a new relationship with reality, a claim to govern the reality. Unlike the legal norm, which expresses an act of will that seeks to govern the reality, such normativities are conceived as immanent to the real, allowing government practices to become more insidious, almost imperceptible, as we see in "algorithmic governmentality". The translation of this article into Portuguese seeks to contribute to the dissemination, in Brazil, of this important debate on politics and the law in contemporary times.
\end{abstract}

Keywords: Normativity. Disobedience. Algorithmic Governmentality.

\footnotetext{
${ }^{*}$ Professor de filosofia política e ética na Université Libre de Bruxelles, autor de livros como Violence de la loi à la Renaissance (Paris, Kimé, 2000), Droit, souveraineté et gouvernementalité (Paris, Léo Scheer, 2005), Gouverner sans gouverner: une archéologie politique de la statistique (Paris, PUF, 2009) e La guerre des philosophes (Paris, PUF, 2019). Desenvolve, entre outros temas, estudos sobre as novas formas de normatividade e controle estatístico, tendo desenvolvido, justamente com Antoinette Rouvroy, a noção de "governamentalidade algorítmica". E-mail: thomas.berns@ulb.ac.be. ORCID: https://orcid.org/0000-0002-8928-4390.

${ }^{\text {i } P r o f e s s o r a ~ d o ~ d e p a r t a m e n t o ~ d e ~ f i l o s o f i a ~ d a ~ U n i v e r s i d a d e ~ d e ~ B r a s i ́ l i a ~(U n B) . ~ D o u t o r a ~ e m ~ f i l o s o f i a ~ p e l a ~ U n i v e r s i d a d e ~ d e ~ S a ̃ o ~ P a u l o ~}$ (USP). E-mail: cecylia.a@gmail.com. ORCID: https://orcid.org/0000-0003-3099-0060.

ii Professor da faculdade de direito da Universidade Federal de Minas Gerais (UFMG). Doutor em filosofia pela UFMG. E-mail: marcofilosofia@gmail.com. ORCID: https://orcid.org/0000-0002-4885-8773.
} 
A norma por excelência, ou seja, a norma a partir da qual se pensa a ideia mesma de normatividade e suas principais qualidades - justiça, soberania, legitimidade, validade, eficácia -, é a norma jurídica. É a partir dela que a filosofia, assim como o cidadão, refletem sobre a ideia de norma. Suas especificidades foram colocadas em evidência por Michel Foucault, que foi justamente aquele que mais contribuiu para tornar manifesto o caráter reducionista dessa compreensão da norma e do poder em geral. Aquilo que Foucault chamava de modelo "jurídico-discursivo" do poder, do qual ele tentou incessantemente se afastar ao revelar seus modelos sucessivos - os mecanismos disciplinares e de segurança -, ainda que compreendidos cada vez mais, todos os três, como componentes nos quais o poder -continua a se exercer 1 , a parece efetivamente em sua especificidade quando o consideramos em relação às suas duas figuras normativas rivais, mais positivas e imanentes. O modelo jurídico-discursivo aparece assim como construído sobre a base transcendente da regra, centrado sobre a soberania ao ponto de parecer ter em vista apenas a sua verificação, pensado como aquilo que se detém ou se transfere e é, sobretudo, negativo, repressivo, ou seja, "bloqueia" os comportamentos.

Eu gostaria de levar em consideração aqui uma qualidade inerente à norma jurídica, tão inerente que tendemos a esquecê-la, qual seja, o fato de que ela é fundamentalmente uma norma à qual é possível obedecer ou desobedecer, até mesmo resistir. Mais exatamente, tratase de uma norma que é pensada e construída em função da possibilidade que ela guarda de ser obedecida ou desobedecida - o que ultrapassa, me parece, a função apenas de proibir, que Foucault coloca em evidência. Essa qualidade é fundamentalmente ligada às outras características da norma jurídica. Sua discursividade só tem sentido quando concebida a partir dessa possibilidade intrínseca da lei de ser obedecida ou desobedecida. Sua construção nos âmbitos representativos dá espaço ao debate e à contradição. Sua não retroatividade, sua publicidade, a sanção que ela prevê, o direito que ela concede a um processo equitativo no qual sua discursividade

\footnotetext{
${ }^{1}$ Mas o fato de a norma se tornar o objeto de um sopesamento, de uma concorrência entre os três modelos em questão, poderia ser interpretado como o acabamento da racionalidade própria ao mecanismo de segurança, uma vez que se trata, nesse caso, de inscrever a norma em um mercado, guiado por uma avaliação estatística de seus efeitos.

${ }^{2} \mathrm{Eu}$ tomo livremente essa expressão emprestada de L. Fuller, A moralidade do direito (The morality of Law, Yale Univ. Press, 1969, p. 33ss.), que lista oito princípios constitutivos da "moralidade interna do direito", a saber, a generalidade, a publicidade, a nãoretroatividade, a inteligibilidade, o caráter não-contraditório, a praticabilidade, a estabilidade da norma e, por fim, o fato de que sua implementação corresponde à sua formulação.
} 
se prolonga, etc., todos esses princípios de legalidade asseguram a "moralidade interna do direito"'2, encarnando a ideia da discursividade da norma, mas deixando entender também como a possibilidade da desobediência é concomitante a essa discursividade.

Essa característica quase trivial pode ser colocada em evidência ao se confrontar a norma jurídica, vista a partir desse ponto de vista, com as formas normativas mais contemporâneas. Por meio dessa confrontação, aparece também a especificidade dessas últimas e a dificuldade na qual elas colocam o filósofo que tenta diagnosticá-las fazendo uso de ferramentas que ainda dependem do registro jurídico-discursivo.

É, antes de tudo, uma nova relação com a realidade que é desenvolvida pelas normatividades contemporâneas. Essas novas normas, cuja eficácia se tornou uma questão central $\left.\right|^{3}$, a ponto de ocupar todo o espaço, são normas que se apresentam como objetivas - pouco importando se de fato o são - e encontram nessa pretensão à objetividade a fonte de seu poder. Em outras palavras, os dispositivos normativos são construídos, são "montados" como expressões do real. Tais atos de governo devem, desde logo, ser claramente dis- tinguidos daquilo que podemos chamar de ação política. Eles devem ser tão objetivos e técnicos quanto possível. Podemos até mesmo dizer que eles devem ser tão invisíveis quanto possível, na medida em que eles seriam portadores de sentido em si mesmos, com referência a uma responsabilidade extrínseca que todo sentido delineia (e, portanto, refletiria a desresponsabilização dos próprios indivíduos). Idealmente, essas novas atividades de governo devem consistir então, essencialmente, em desvelar, mostrar, e não em agir nem "fazer" o que quer que seja. Em suma, na maior medida possível, consiste em governar sem governar..$^{4}$ Aquilo que é essencial e próprio a esse tipo de governo decorre então do tipo de relação com o real que se delineia: o real é pensado como algo que existe e funciona por si mesmo, que não tem nenhuma necessidade de ser instituído (vemos, aqui, um ponto de partida que encontramos desde Hume, radicalmente oposto àquele que, na grande tradição da filosofia política moderna, quis pensar o comum a partir da figura inaugural do contrato social). $\mathrm{O}$ real deve apenas ser dito, ser retomado, ser definido, ser tornado mais consistente. Mas isso, entenda-se bem, para

\footnotetext{
${ }^{3} \mathrm{Na}$ medida mesmo em que a eficácia, ao menos até a emergência da análise econômica do direito, foi sempre, para o continente jurídico, uma questão secundária. Exceto se a considerarmos como algo que encontra toda a sua consistência na verificação quase solipsista da soberania: poderíamos quase dizer que, idealmente, do ponto de vista da teoria do direito, a eficácia da lei era inteiramente relativa à sua efetividade, não aos seus resultados.

${ }^{4}$ Ver meu livro Governar sem governar: uma arqueologia política da estatística (Gouverner sans gouverner. Une archéologie politique de la statistique, PUF, 2009). Ainda sem tradução para o português ( $\mathrm{N}$ dos T.). Por essa expressão, eu não entendo de forma alguma que não há governo. Ao contrário, nunca se governou tanto. Mas esse poder de governar decorre de uma retenção, de uma aparente preocupação de se colar ao real.
} 
dar lugar ao governo. A definição mais geral desse governo que se abstém de governar reside na relação que ele estabelece com o real. Trata-se de governar a partir do real, a partir das atividades existentes, e não mais governar $o$ real, ou o concreto, entendendo que o concreto e seu governo seriam objetos de decisão. Trata-se, então, de governar como se nos contentássemos em recolher aquilo que já está aí, em recolher a atividade humana, tomada em consideração e mostrada como viva e substancial.

Vejamos, a partir de agora, três aspectos mais importantes dessa aderência ao real, própria aos dispositivos normativos contemporâneos:

- Em primeiro lugar, os dispositivos normativos contemporâneos parecem, mais frequentemente, se contentar sempre em apenas colocar em questão a definição das coisas. Nesse sentido, eles têm, cada vez mais, a forma de uma especificação técnica ou ainda de uma certificação, algo meramente sugerido, repousando sobre a conformidade em relação ao que aparece como o modelo de definição de um elemento de nossa realidade (dois exemplos evidentes: as normas ISO e o DSM). Idealmente, trata-se somente de dizer ou de reconhecer as coisas tais como elas são, não como elas deveriam ser, a ponto de poder livrar-se de toda força obrigatória.

- Em segundo lugar, os dispositivos normativos contemporâneos interpelam, antes de tudo, aqueles sobre os quais incidem (indivíduos, empresas, centros de pesquisa...), para que se deem conta de suas próprias atividades. É, na medida do possível, por meio dessa ação de relato (reporting) de si mesmo que a ação normativa se realiza. Uma das principais ferramentas normativas é o relatório (rapport), que permite em seguida o desenvolvimento de outras práticas normativas mais específicas, como a avaliação, a classificação etc. Temos aí, ao que parece, um fundo comum à maioria dos contextos normativos contemporâneos, que é urgente questionar e que se desenvolve explorando, de uma maneira nova, o modelo da confissão ou do reconhecimento.5

- Em terceiro lugar, os dispositivos normativos contemporâneos inscrevem-se, majoritariamente, em uma racionalidade atuarial. Eles são geralmente nutridos, acompanhados, justificados, reforçados e corrigidos pelas técnicas estatísticas (no nível mais geral, somos sempre governados por dispositivos estatísticos). Isso é ainda mais perceptível e constante nas novas técnicas estatís-

\footnotetext{
${ }^{5}$ Ver os dois artigos que escrevi com G. Jeanmart, "Relatório / Confissão" ("Reporting / Confession », in Multitudes, $\mathrm{n}^{\circ}$ 36, 2009) e "O relatório como resposta da empresa responsável: promessa ou confissão (a partir de Austin e Foucault)" (« Le rapport comme réponse de l'entreprise responsable : promesse ou aveu (à partir d'Austin et Foucault) », Dissensus, 3, 2010, pp. 117-137, http://popups.ulg.ac.be/dissensus/document.php?id=701).
} 
ticas que repousam sobre práticas de coleta massiva e não seletiva de dados, que exploram grandes quantidades de dados (big data) por meio da mineração de dados (datamining), o que permite produzir normas que aparecem como a expressão mesma da realidade, uma vez que esses procedimentos parecem ter se livrado de todo apoio nas subjetividades (ver adiante). Nós, cada vez menos, devemos ou podemos consentir em ceder a informação (que deixa de ser a marca da subjetividade). Ao invés disso, nós a abandonamos. E o tratamento que é reservado à informação, para lhe conceder um valor normativo, reivindica cada vez menos a expressão de uma hipótese sobre o social. Ele se contenta em aproveitar as correlações que aparecem e que são cada vez mais suficientes para que haja uma norma.

Definir o real, incitar cada um a produzir um relato de sua realidade, fazer emergir estatisticamente normas da realidade. Essas são as três questões em jogo, evidentemente correlacionadas, colocadas pelas novas formas de normatividade. Essas questões permitem que essas normatividades sejam pensadas como imanentes ao real. E permitem, de maneira mais global, que os atos de governo apareçam como fundamentalmente habitados por um caráter inofensivo, o que garante o po- der mesmo desses atos, assim como sua transmissão. Em outras palavras, isso confere a possibilidade de governar ainda mais, de governar sem fim (nos dois sentidos do termo).

Gostaria, de maneira mais específica, de colocar em evidência esse governo sem fim, detendo-me em alguns aspectos do terceiro tipo de dispositivo assinalado, a saber, aquele que organiza, de maneira estatística, as práticas de governo contemporâneas (eu entendo aqui por práticas de governo a ideia geral de uma ação estruturada sobre os comportamentos individuais e coletivos, qualquer que seja a fonte dessa ação). Isso mostra, mais particularmente, como a evolução contemporânea dessas práticas de governo estatístico induz, precisamente, um deslocamento essencial quanto às possibilidades de resistência a elas, até o ponto em que as normas assim produzidas mudam totalmente de natureza, se a pensamos em referência ao modelo da norma jurídico-discursiva.

Em conjunto com Antoinette Rouvroy, já descrevi longamente o funcionamento daquilo que nós chamamos a "governamentalidade algorítmica", para distinguir, deste modo, as especificidades das práticas estatísticas automatizadas, atualmente desenvolvidas em todas as esferas da atividade humana (política de segurança, práti-

\footnotetext{
${ }^{6}$ Ver T. Berns e A. Rouvroy, "Governamentalidade algorítmica e perspectivas de emancipação: o díspar como condição de individuação pela relação?" ("Gouvernementalité algorithmique et perspectives d'émancipation. Le disparate comme condition d'émancipation par la relation ? ", Réseaux, 2013/1, n 177, La Découverte, p. 163-196; tradução para o português publicada na
} 
cas médicas, publicidade direcionada etc.). ${ }^{6}$ Deter-me-ei, aqui, apenas em alguns elementos que permitem ressaltar uma tentativa de evitar qualquer possibilidade de resistência por parte dos sujeitos envolvidos nessas práticas:

- Os dados, constitutivos daquilo que é cada vez mais chamado de Big Data, são coletados e conservados (o momento do datawarehousing), de preferência por padrão. Isso não significa, de maneira alguma, que eles são "roubados" dos sujeitos envolvidos. Eles são, sobretudo, abandonados: dados quaisquer, anódinos, perfeitamente heterogêneos uns em relação aos outros, em geral anonimizados, sem valor intrínseco e, sobretudo, sem finalidade. O uso que será feito deles não é nunca definido no momento de sua coleta. Esses dados não podem ser objeto de uma cessão, nem de um roubo (nem, portanto, da recusa que acompanha o sentimento desse último). Esse evitamento radical da esfera da intencionalidade - que demanda, por princípio, ser ligada a um questionamento acerca das finalidades -, assegura, ao mesmo tempo, a tolerância que podemos testemunhar em relação à constituição daquilo que se assemelha a uma duplicação digital da realidade, assim como a pretensão à mais perfeita objetividade dessa duplicação, que não sofre, propriamente falando, de nenhuma forma de subjetividade!

- O tratamento automatizado dessas massas de dados não triados a priori (pelo datamining), tendo em vista fazer emergir correlações, comporta as mesmas qualidades de aderência objetiva à realidade, uma vez que o datamining parece permitir precisamente que se faça emergir saberes, por mais rudimentares que sejam, sem que hipóteses sejam previamente expressas (o típico da aprendizagem de máquina [machine learning] reside na produção automatizada das próprias hipóteses). Assim, novamente, é a própria marca de toda forma de subjetividade "viciando" os saberes que parece poder ser evitada. E essa elisão aparece como um garante da força dos saberes assim produzidos.

- Enfim, quanto às ações sobre os comportamentos individuais ou coletivos, tirados desses saberes estatísticos (por meio do perfilamento), elas testemunham novamente a máxima elisão dos sujeitos (apesar da aparente personalização dos serviços propostos). 7 Isso porque são mais as propensões dos sujeitos, e cada vez menos suas ações, que

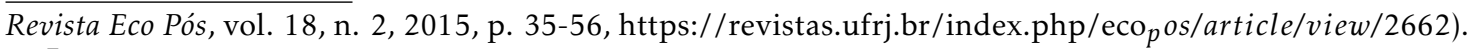

${ }^{7}$ Os quais, aliás, poderiam, cada vez mais, abandonar toda forma de uso de categorias discriminatórias, forçosamente coletivas (as antigas "médias" da estatística de Quételet), em benefício de uma adequação perfeita aos devires singulares.

${ }^{8} \mathrm{M}$. Foucault, Segurança, território, população: curso dado no Collège de France (1977-1978) (Sécurité, territoire, population. Cours au Collège de France, 1977-1978, Seuil / Gallimard, 2004, leçon du 18 janvier 1978, p. 8 ou 21-22; tradução para o português de Eduardo 
são atuadas por antecipação (é a ação sobre o provável ou mesmo o possível, já identificada por Foucault ${ }^{8}$ como sendo próprio aos mecanismos de segurança do biopoder). O que pode ser normatizado, cada vez mais, são os ambientes, excluindo toda forma de coerção direta sobre os comportamentos dos sujeitos.

Nesse quadro absolutamente exemplar da produção normativa contemporânea, a relação da norma é, como tal, invertida. A norma jurídica, como norma por excelência, era pensada como aquilo que agia essencialmente sobre os comportamentos, ou mesmo os constrangia, pressupondo, sobre essa base, sua expressão discursiva prévia (idealmente objeto de debate), deixando espaço, necessariamente, para o seu desvio- a desobediência -, que pode dar lugar ao prolongamento do valor discursivo da norma (idealmente no âmbito de um procedimento judiciário). Aqui, ao contrário, a norma é precisamente aquilo que não pode ser dito (qualquer que seja a maneira de dizer - até mesmo um algoritmo poderia, em princípio, responder à ideia de uma discursividade da norma). Isso em nome de seu caráter constantemente evolutivo (ou, então, no caso das normas mais estruturantes, como as sequências de algoritmos que permitem o funcionamento dos motores de busca mais utilizados, pois se acredita que o segredo deles permite um comportamento tão natural quanto possível). A norma aparece, ao contrário, como aquilo que segue, da maneira mais adequada e mais evolutiva, os comportamentos, tirando daí sua potência, até o ponto no qual podemos dizer que não se trata, de modo algum, de tornar os comportamentos adequados às normas, mas sim de tornar as normas adequadas aos comportamentos: a norma se torna o objeto mesmo da norma..$^{9}$ Sobre essa mesma base, enfim, a norma não é mais pensada como aquilo que devemos obedecer e que, portanto, podemos desobedecer. Ao invés disso, ela é pensada como aquilo que não é mais possível desobedecer. O conjunto do ambiente é organizado e reorganizado sem cessar em função das propensões de cada um. A eventual diferença de um comportamento em relação à norma dá imediatamente lugar a uma revisão dessa última.

Essa mudança na natureza mesma da norma e na relação geral que ela estabelece com o real corresponde também a uma transformação quanto à natureza do objeto da norma. De ma-

\footnotetext{
Brandão publicada em São Paulo, Martins Fontes, 2008, aula de 18 de janeiro de 1978).

${ }^{9}$ Desse ponto de vista, parece-me cada vez mais fundamental analisar os fenômenos de implementação das normas (nas empresas, nos centros de pesquisa, nos serviços públicos...), voltando-se para o fato de visarem tornar as normas as mais adequadas possíveis à realidade concernida. Reciprocamente, o papel daqueles que se submetem às normas parece ser garantir a sua efetividade, até o ponto em que o essencial das práticas de gestão que decorrem dessas normas consiste em lhes dar consistência, pelo desenvolvimento de uma multiplicidade de ferramentas que se aparentam a uma pura transmissão normativa.
} 
neira espontânea, pensamos que uma norma incide sobre as substâncias, as realidades substanciais, tão individuais quanto possível (um sujeito, um objeto, um estatuto, eventualmente coletivos ou apresentados por grandes números, médias...). Como se uma ação normativa só pudesse ser relativa a um objeto considerado como substancial, localizável, que está submetido à norma (e, mais uma vez, obedece-lhe ou não). Ora, é preciso constatar que o conjunto do processo normativo se dirige cada vez mais para as relações, mais do que substâncias individuais, ao ponto até de parecer tornar essas últimas relativas às primeiras: os dados transmitidos são relações ${ }^{10}$ e somente subsistem como relações. Os saberes gerados são relações de relações. E as ações normativas que decorrem daí são ações sobre as relações (ou os ambientes) referidos às relações de relações. Não se trata, entretanto, de concluir que uma ontologia da relação teria, assim, tomado a dianteira, em nível político, sobre a tradicional ontologia da substância. Tratase apenas que as relações, elas mesmas, desde que o devir se tornou o objeto mesmo do governo, tornaram-se os primeiros apoios e objetivos das ações normativas, evitando, desse modo, os sujei- tos da norma (e reduzindo a nada, assim, mais uma vez, a questão da obediência ou da desobediência).

Insistamos, para concluir, sobre um último ponto. Se o quadro traçado aqui conduz facilmente demais ao impasse sobre a presença, por detrás dessa produção normativa, de interesses diversos (mercantis, securitários, políticos ou geopolíticos...), movidos por suas finalidades próprias, é porque me parece urgente insistir sobre a expansão do campo normativo, colocando em evidência o fato de que essa expansão é sempre mais conduzida pela aparente inofensividade intrínseca às normas produzidas, sua pretensão à objetividade, ou mais precisamente sua aderência ao real. Isso significa que, mais do que uma denúncia das assimetrias estruturais encobertas pelas normas (o discurso marxista), e mais do que uma preocupação em relação aos direitos dos sujeitos sobre os quais incidem as normas (a questão do consentimento esclarecido do discurso jurídicoliberal), nós temos cada vez mais necessidade de direcionar nossa atenção sobre as normas elas mesmas, na medida em que elas são integralmente postas em ação em toda forma de realidade, aderentes a ela e tirando dessa aderên-

\footnotetext{
${ }^{10}$ A palavra "relação", entendida aqui em seu sentido mais bruto, menos habitado, pelo qual nós qualificamos o dado, serve-nos somente para atestar uma operação que liga a e b e é capaz de ignorar o que está por detrás dos termos assim ligados. Como, aliás, mostramos, toda força do governo algorítmico reside in fine em sua capacidade de "monadologizar" essa relação, ao ponto em que essa relação não mais consegue apreender o devir que seria próprio à relacionalidade (ver T. Berns e A. Rouvroy, "Governamentalidade algorítmica e perspectivas de emancipação: o díspar como condição de individuação pela relação?”, op. cit., e T. Berns, " Not individuals, Relations: What Transparency is really about. A theory of algorithmic Governmentality », Transparency, Society, Subjectivity - Critical Perspectives, ed. Springer, 2018, p. 243-257). Ainda sem tradução para o português" (N dos T.)
} 
cia sua potência, dotadas, em outras palavras, de uma vida própria. Essa fusão da norma e da realidade parece tornar toda resistência esquizofrênica. Ela exige, para além de sua análise, cuidar, cultivar e, talvez, multiplicar nossas heterotopias.

\section{Referências}

BERNS, T. "Not individuals, Relations: What Transparency is really about. A theory of algorithmic Governmentality ", Transparency, Society, Subjectivity - Critical Perspectives, ed. Springer, 2018.

BERNS, T. Gouverner sans gouverner. Une archéologie politique de la statistique, PUF, 2009.

BERNS, T.; ROUVROY, A. "Gouvernementalité algorithmique et perspectives d'émancipation. Le disparate comme condition d'émancipation par la relation? », Réseaux, 2013/1, n 177, La Découverte, p. 163-196; [tradução para o português publicada na Revista Eco Pós, vol. 18, n. 2, 2015, p. 35-56, https://revistas.ufrj.br/index.php/eco_pos/ article/view/2662

BERNS, T.; JEANMART, G. « Le rapport comme réponse de l'entreprise responsable : promesse ou aveu (à partir d'Austin et Foucault) », Dissensus, 3, 2010, pp. 117-137, http://popups.ulg.ac.be/dissensus/document.php?id=701).

BERNS, T.; JEANMART, G. "Reporting / Confession ", in Multitudes, n 36, 2009.

FOUCAULT, M. Sécurité, territoire, population. Cours au Collège de France, 1977-1978, Seuil / Gallimard, 2004, leçon du 18 janvier 1978, p. 8 ou 21-22 [tradução para o português de Eduardo Brandão publicada em São Paulo, Martins Fontes, 2008].

FULLER, L. The morality of Law, Yale Univ. Press, 1969.

Recebido: $10 / 12 / 2020$

Aprovado: $20 / 12 / 2020$

Publicado: $31 / 01 / 2021$ 
